Article

\title{
Definition of Reference Models for Power, Weight, Working Width, and Price for Seeding Machines
}

\author{
Tatevik Yezekyan ${ }^{1, *}$, Francesco Marinello ${ }^{1}\left(\mathbb{D}\right.$, , Giannantonio Armentano ${ }^{2}$, Samuele Trestini ${ }^{1}$ (D) \\ and Luigi Sartori ${ }^{1}(\mathbb{D}$ \\ 1 Department of Land, Environment, Agriculture and Forestry, University of Padova, Via dell'Università 16, \\ 35020 Legnaro, Italy; francesco.marinello@unipd.it (F.M.); samuele.trestini@unipd.it (S.T.); \\ luigi.sartori@unipd.it (L.S.) \\ 2 Edizioni L'Informatore Agrario srl, Via Bencivenga - Biondani, 16, 37133 Verona, Italy; \\ g.armentano@informatoreagrario.it \\ * Correspondence: tatevik.yezekyan@phd.unipd.it; Tel.: +39-380-244-2648
}

Received: 22 October 2018; Accepted: 26 November 2018; Published: 29 November 2018

check for updates

\begin{abstract}
Machine functional parameters define fleet composition and management and, thus, play an important role in economic and environmental performance. Large availability of programming methods and decision support systems are available in the market, however, there is still a lack of applicative tools to forecast the perceived and necessary technical parameters and machinery price options to complete tasks. In the current research, most correlated functional parameters for four group of seeding machines were determined with the application of linear and multiple linear regression analyses. Power, weight, working width, number of rows, and list price were studied, and reference equations were developed for seed drills, precision, combined and no-tillage planters. Two statistical analyses models were, therefore, developed for each of the groups in order to allow evaluation and prediction of performance and cost, thus contributing to the selection process optimisation and perceived choice of the needed implement.
\end{abstract}

Keywords: seeding machine; functional parameter; operation research; modelling; linear programming; fleet management

\section{Introduction}

Rural mechanisation and fleet organisation have an essential impact on agricultural production and on sustainable development of farm institutions. Accordingly, farmer's decision on the acquisition of a new machinery and replenishment of the fleet needs to be based on the complex interaction of economic, environmental, and social criteria and supported by the field stockholders (dealers, consultants, regional or national authorities, etc.) [1,2]. Despite its importance, there are several aspects that have a significant impact on the farmer's buying decision behaviour and decision-making process. The perception that higher performances might increase profits or might be needed one day often give an inverse effect and bring the selection process to a more complex stage. The choice of the machine based on brand (brand name, loyalty, band familiarity, and "inertial" choice), on advanced equipment provided with the implement [3], or on available financial resources change the concept of fleet management, leading to the adaption of badly scaled machinery both from the dimensional and from the functional point of view $[4,5]$. Such an approach can be understandable in the case of tractors, which have a multi-purpose and sometimes unpredictable use, while it is unacceptable for agricultural implements which, conversely, must be optimised for well-defined operations, thus often playing a crucial role for the success of crop production. The reasons behind unbalanced choices have to be ascribed not only to low awareness of farmers, but also to the lack of knowledge and reference 
models supporting the same selection process [6]. This is particularly true and critical for one of the most important agronomic operations: sowing.

The primary goal of planting operation is to obtain the maximum net return per hectare by the establishment of an optimum plant population according to the agronomic requirements [7]. According to Murray et al. [8], there are two broad optimisation aspects of plant establishment: the quality of the seeds and the selection of appropriate seeding machine. Wide availability and high variability of functional characteristics of seeding machines in the market make the selection process often difficult and confused for the farmer. Simplification of the practices for definition of the eligible parameter-price relation can reduce the complexity of the estimation approach by operation and correct distribution of the available resources. Despite the availability of several decision support systems (DSS) and farm management digital tools [9-13], none provide a systematic approach for the definition of the farm fleet, and specifically for the choice of an implement. This is mainly due to the lack of reference equations which create a base for modelling functional parameters and allow forecasting costs or performances.

In the last decades, technological advances adopted in agricultural production and associated development of units contributed to more specialised and complex farm planning management. The experience-based traditional planning method has been replaced with the operation research analytical approach and computer simulation models, called to maximize the predictable output with the minimisation of investments and side effects. Operation research (OR) is an analytical method intended for problem-solving and decision-making with consideration of basic components and definition of the solution by mathematical analysis [14]. Most common techniques used in the operation research are linear programming, simulation, mixed integer programming [15]. The application of linear programming models includes large frames in agriculture planning, which mainly can be classified as follows: crop production (planning, prediction, and protection), farm mechanisation, farm cost calculation, assessment of agricultural policies, soil stress, and environmental protection [16-21]. Despite the fact that the objectives of the operation management units are different, they are linked: as a consequence it is possible to reapply the designed tools, merge or use the outcomes of methods as initial data for further simulations and research, ensuring the balanced development of the chain (crop production management, farm equipment evaluation and set definition, soil compaction calculation, carbon footprint) [14,22-24]. Such approach eventually leads to the practical and regulatory enhancement of the management, definition of the new target units and polices for the preferred level of consideration (farm, region, government) [2,25-27]. Although the interaction between sectors is high and all units have own influence on the agricultural system, the fleet management and mechanisation has the highest level of consequence (investment, soil, environment).

For minimisation of the mechanisation costs, a multifarm machinery use program was developed by Camarena et al. [28], consisting of a mixed integer linear program (namely Multipredio) intended for the selection of agricultural machinery with the multifarm approach, operation time, and fleet management.

Based on a participatory approach and consequent system analysis the conceptual model of a Fleet Management System was developed by Sørensen and Bochtis [13]. The approach involves identification of the scope of the system, activities and their requirements, conceptual modelling and information-needs modelling. The developed system includes mainly all available information technology advances adapted in agriculture for organisation of farm management: on-line positioning of vehicles, machine monitoring/tracking, improved general knowledge of the production process and management, automatic invoicing and documentation system, coordination of multiple machines (farmers, contractors), route, and path guidance, etc.

To support farmers with field operation planning (e.g., traffic system, driving direction, refilling position), machinery dimensioning (e.g., tank capacity, operating width, etc.) and to increase the operational efficiency an object-oriented model for simulating agricultural in-field machinery activities have been developed and applied by Hameed et al. [29]. 
A web mobile application "Agricultural Machine App Cost Analysis" based on a cross-platform approach was also developed by Sopegno et al. [30], allowing determination of machinery costs in different field operations, based on user expectations with customer-driven Quality Function Deployment approach.

Agricultural mechanisation and interpretation of received information have deeply changed in the last decades. Development of information and communication technologies brought to the development of new tools applied in every field, allowing simplification of the analyses, increment of the effectiveness and maximization of considered unit productivity. By way of example, this purpose lead to the development of ISO 11783 international standard for communication of agricultural machinery (ISOBUS), implements, on-board computer technologies, and provision of more effective connection between these entities. Therefore, there is a need for organisation of the information flow pathway, which means filtration of collected information, transition to appropriate knowledge, and consequent decision support. Based on that concept Fountas et al. [31] developed a dynamic model for farm machinery management, which allows farming related data and corresponding farm management actions to be recorded and further analysed in real-time. Soft systems methodology were then used for "farm machinery management information system" in order to analyse the use of farm machinery and the management of generated information from agricultural machinery and implements.

Thus, more than a dozen models have been developed for farm machinery planning, selection, forecasting, scheduling, logistics, evaluating capital investment decisions [12,16,32-35]. However, most of the reference equations for machine cost calculation models are based on economic analysis with consideration of fixed and variable costs of machines. In practice, the use of developed models and simulations is limited to research and decision support services, while individual farmers would need simple reference cost-based methods or tools to make equipment investment decision. Thus, the management of farm fleets (tractors and implements), as well as machinery selection and planning, must take into account different parameters, concerning not only the cost of the machines but also their dimensions, power, weight, working width, working speed (or efficiency), etc. It is worth noting that a fully comprehensive approach should take into consideration also repair and maintenance costs, which play an important role, especially with reference to management costs and efficiency. However their computation is deeply influenced by the specific working conditions, and a quantification is typically done on the basis of the specific farm records. On the other hand, mentioned information related to an agricultural machine is eventually influencing the impact of that machine on productivity, on the return on the investment, and also on the environment. Simplified equation models are needed to support decisions at the different applied management levels (farmer, stakeholder, government), with sufficient certainty according to the studied market.

The aim of the current work is to identify the most relevant technical parameters of seeding machines, recognise correlations and dependencies, and eventually define equation models which allow prediction of most important characteristics.

\section{Materials and Methods}

\subsection{Seeding Machines}

Crop planting process involves seed placing in the soil in the predetermined depth, random scattering or dropping of seeds on the field surface $[8,36]$. The exact definition of the planting description and equipment depends on the placement method, which can be classified as follows according to Bainer et al. [7]:

- random scattering of seeds over the surface of the field is described as a broadcasting distribution method,

- random dropping and covering of seeds in the furrow to give definite rows is the drill seeding pattern, 
- accurate placing of single seeds at approximately equal intervals in rows dedicated to the precision planting,

- random dropping of groups of seeds at about equal intervals in rows and accurate and indexed placement of hills or groups of seeds to give rows in two perpendicular directions are called hill dropping and cheek row planting, respectively, and

- $\quad$ single or multiple seed delivery in individual holes that have been dug in the seedbed is called dibble planting.

Accordingly, to the mentioned patterns planters can be divided into broadcast, drill, precision, dibble, and specialised. In the current research most applied seeding machines types went under research, and according to collected data the implements were classified as planters for precision, combined and no-tillage crop management, and seed drills. The inclusion of combined and no-tillage subgroups of implements in the research is due to the idea to foresee the behaviour of the developed models and to define the possible correlation according to the different crop management approaches.

It is worth noting that new technologies are rapidly arising and being proposed to enhance seeding machines performances, as e.g.: satellite systems (Global Navigation Satellite System), seed counting devices, integrated infrared sensors, down force controllers, etc. Such systems are most often available as optional equipment, and for these reason have not been included in the analysis.

\subsection{Reference Database}

The present work takes advantage of a reference database collecting information on most important technical characteristics and prices of agricultural machines available in the European market. Such database is promoted by the same authors and regularly populated by machine constructors with the assistance of Informatore Agrario srl. (Verona, Italy) It includes over 6000 models of the main agricultural machinery categories: tractors, harvesters, implements for tillage and sowing, crop protection, fertilisation, hay-making, etc. Due to its relevance, one of the most populated categories is that of seeding machines, which covers main technical specifications of 463 models of 17 different producers from Italy, Argentina, France, Brazil, Denmark, Norway, Austria, and Germany. The collected information was done according to Table 1 details: however, in some cases, not all of the parameters were available or meaningful for all of the machines.

Table 1. Considered data of seeding machines according to the information provided by constructors.

\begin{tabular}{cc}
\hline Characteristic & Description/Type \\
\hline Model & constructing company, series, name \\
drill/planter \\
Type of machine & trailed, semi-mounted, front/mid/rear mounted; needed power \\
sttachment to the tractor & mechanical/pneumatic \\
Tank capacity & furrow opener device \\
Seed distribution & the number and minimum/maximum distance of rows \\
Soil-engaging components & standard tires, hydraulics, electronic controls \\
Working width & total width, weight \\
Other equipment & basic machine configuration \\
Dimensions &
\end{tabular}

The range for minimum and maximum values of the considered variables in accordance with the available dataset is presented in Table 2 , which additionally create a brief picture of the machinery set studied within the current work. 
Table 2. The range for minimum and maximum values of the considered variables according to the dataset.

\begin{tabular}{ccccc}
\hline Variables & Precision & Combined & No-Tillage & Row \\
\hline Power, $\mathrm{kW}$ & $30-180$ & $60-260$ & $45-160$ & $40-200$ \\
Tank capacity, $\mathrm{L}$ & $120-720$ & $360-4350$ & $50-2500$ & $240-3000$ \\
Working width, $\mathrm{m}$ & $1-9$ & $2.5-6$ & $1.2-6.5$ & $2-6$ \\
Weight, kg & $580-3460$ & $580-8000$ & $1200-9000$ & $480-12,300$ \\
Price VAT excl., $€$ & $9500-63,000$ & $7000-123,000$ & $23,900-124,000$ & $4400-120,000$ \\
Number of rows & $4-12$ & $15-48$ & - & $13-48$ \\
Work capacity ha/h & $8-90$ & $15-48$ & $10-65$ & $16-60$ \\
Power/working width, $\mathrm{kW} / \mathrm{m}$ & $8.8-34$ & $17.5-73.3$ & $17-34$ & $11-42$ \\
Power/number of rows, $\mathrm{kW} / \mathrm{n}$ & $6.2-19.5$ & $2.1-9.2$ & - & $1.3-5.3$ \\
Weight/working width, $\mathrm{kg} / \mathrm{m}$ & $157-1071$ & $194-2350$ & $377-1654$ & $148-2040$ \\
Weight/number of rows, $\mathrm{kg} / \mathrm{row}$ & $110-500$ & $22-180$ & - & $18-255$ \\
\hline
\end{tabular}

The dataset includes 341 implements, which are classified as planters: 160 precision planters, 46 intended for no-tillage management, and 135 models of combined planting process. The rest of the seeding machines under research compiled with 122 seed drills. Available data represent a clear figure of the present crop establishment machine market and allow to produce comparisons and models for different groups of commercial planters.

\subsection{Data Analysis}

For a definition of the most correlated functional parameters of commercial seeding machines and their influence on the performance of the machines and price, data were classified into four main groups according to the type of machine (seed drills, combined, no-tillage, and precision planters) and analysed separately. Power, working width, number of rows, weight, tank capacity, list price were investigated as main variables for applied statistical analyses.

Dependencies between considered variables were studied with the application of linear and multiple linear regression analyses. The relevance of the models was quantified by means of correlation studies and dependences modelled according to linear (1) and multiple linear (2) characteristic equations:

$$
\begin{gathered}
y=m_{1} \cdot x+q \\
y=\sum_{i} m_{i} \cdot x_{i}+q
\end{gathered}
$$

where $x$ and $y$ represent respectively independent and dependent variables, $m_{i}$ is the slope (or linear coefficient) related to the $i$-th independent variables, $q$ is the intercept between $y$ and $x$ variables.

Microsoft Excel (Microsoft Corporation, Redmond, WA, USA) was used for the creation of correlation matrices, regression analyses and model development for both of the approaches. According to the simple linear regression analysis data reported regarding Pearson correlation coefficient $r$, slope $m$ and intercept $q$ of the linear models. As an alternative to the linear models for more detailed research of the performances of the machines and price correlation definition, stepwise regression analysis were applied. Compared to the first type of analysis, multiple linear regression analysis allows to identify and avoid misleading regression of variables and overfitting of studied data. This type of models are more complex, and the implementation with simulated scenarios might create some constraints, where optimisation or definition of break-even points are needed, though they can be used whenever a deeper description is needed for different parameters. The stepwise regression model explains the relationship between the response and explanatory variables. In current work the response (dependent) variables were represented by power, weight, working width and price; explanatory (independent) variables converged to tank capacity, working width, weight, and power. Price was not included between independent variables, being itself a function of machine performance. Multiple linear regression output was evaluated in terms of adjusted multiple coefficient of determination (adjusted $R^{2}$ ). 


\section{Results}

\subsection{Linear Modelling}

\subsubsection{Seed Drills}

Seed drills are extensively used machines implemented in the case of both winter and summer crops. Such machines randomly drop seeds in furrows and form definite rows with established density of plants (in terms of seeds per hectare) and fixed rows distances (typically ranging between 80 and $350 \mathrm{~mm}$ ). Due to the narrow row spacing drills are often known as solid crop seeding machines. Pneumatic and gravity drop distribution systems tolerate considerable variation in both seeding rate and uniformity of seed spacing without a significant loss in yield [8].

The linear modelling and correlation analysis for seed drills exhibited relatively high Pearson coefficients in particular between price and weight $(r=0.97)$, number of rows and working width $(r=0.95)$, weight and power $(r=0.90)$, as reported in Table 3. Slightly lower correlation was also found between price and power $(r=0.87)$, as well as between price and tank capacity $(r=0.84)$. Such correlations are quite reasonable since the size and, thus, the weight of the machine depends on the number of rows (which have standard distances), while single elements allowing seeding in each row are quite similar from different producers (shapes are slightly changing, but overall dimensions are quite similar).

Table 3. Correlation matrix of Pearson coefficient $r$ for functional parameters of seed drills.

\begin{tabular}{ccccccc}
\hline Seed Drills, $\boldsymbol{r}$ & $\begin{array}{c}\text { Required } \\
\text { Power, } \mathbf{k W}\end{array}$ & $\begin{array}{c}\text { Working } \\
\text { Width, } \mathbf{m}\end{array}$ & $\begin{array}{c}\text { Number of } \\
\text { Rows }\end{array}$ & $\begin{array}{c}\text { Tank } \\
\text { Capacity, } \mathbf{L}\end{array}$ & Weight, kg & $\begin{array}{c}\text { Price VAT } \\
\text { Excluded, } \boldsymbol{\epsilon}\end{array}$ \\
\hline Required power & 1 & & & & & \\
Working width & 0.487 & 1 & & & & \\
Number of rows & 0.478 & 0.946 & 1 & & & 1 \\
Tank capacity & 0.709 & 0.453 & 0.456 & 0.788 & 1 & 1 \\
Weight & 0.897 & 0.411 & 0.428 & 0.839 & 0.977 & \\
Price VAT excl. & 0.869 & 0.484 & 0.511 & & & \\
\hline
\end{tabular}

Linear coefficient and intercept were estimated for all of the variables combinations according to the linear regression analysis. Results are summarized in Table 4. For seed drills, it can be noticed how for each additional tonne of the machine, a power supply of $14 \mathrm{~kW}$ needs to be counted, while for the same weight, a volume of tank capacity of about 0.27 cubic meter has to be taken into account. With regard to needed investment, a starting price of at least $4776 €$ has to be considered, increasing by $10,660 €$ for each additional tonne of weight. Heavier and larger machines are influenced by the number of rows and have a consequent effect on required power which can be quantified as an initial need of about $18 \mathrm{~kW}$, increasing by $13.9 \mathrm{~kW}$ for each additional $\mathrm{m}$ of working width.

Table 4. Linear coefficient and intercept matrix for functional parameters of seed drills.

\begin{tabular}{|c|c|c|c|c|c|c|c|}
\hline & Seed Drills & $\begin{array}{c}\text { Required } \\
\text { Power, kW }\end{array}$ & $\begin{array}{l}\text { Working } \\
\text { Width, m }\end{array}$ & $\begin{array}{l}\text { Number } \\
\text { of Rows }\end{array}$ & $\begin{array}{c}\text { Tank } \\
\text { Capacity, L }\end{array}$ & $\begin{array}{l}\text { Weight, } \\
\text { kg }\end{array}$ & $\begin{array}{c}\text { Price VAT } \\
\text { Excluded, } €\end{array}$ \\
\hline \multirow{6}{*}{$m$} & Required power & & 13.85 & 1.651 & 0.032 & 0.014 & 0.001 \\
\hline & Working width & 0.017 & & 0.115 & 0.0007 & 0.0002 & $2.404 \times 10^{-5}$ \\
\hline & Number of rows & 0.138 & 7.794 & & 0.006 & 0.002 & 0.0002 \\
\hline & Tank capacity & 15.69 & 285.1 & 34.88 & & 0.269 & 0.026 \\
\hline & Weight & 58.11 & 756.2 & 95.87 & 2.306 & & 0.089 \\
\hline & Price VAT excl. & 614.9 & 9726 & 1248 & 26.81 & 10.66 & \\
\hline \multirow{6}{*}{$q$} & Required power & & 17.74 & 21.54 & 39.82 & 47.06 & 42.21 \\
\hline & Working width & 2.392 & & 0.395 & 2.930 & 3.218 & 3.055 \\
\hline & Number of rows & 18.09 & -0.204 & & 22.32 & 24.62 & 23.17 \\
\hline & Tank capacity & -207.7 & -168.9 & -115.1 & & 457.0 & 315.9 \\
\hline & Weight & -2456 & -1254 & -1203 & -516.2 & & -362.7 \\
\hline & Price VAT excl. & $-21,123$ & $-14,486$ & $-14,235$ & -2597 & 4776 & \\
\hline
\end{tabular}




\subsubsection{Combined Planters}

Combined planters can be resembled as a combination of tillage and planting operations, mainly designed for cereals and grains. Being equipped with cultivation and planting ground tools they provide full-width cultivation for weed control, seedbed preparation, re-compaction, and sowing in one pass of the machine. Such kind of planters are heavier due to the implementation of a variety of cultivation tools and larger hoppers.

As can be seen from Table 5, high correlations for combined planters were found between price and weight $(r=0.88)$ and also between price and number of rows $(r=0.75)$. Slightly lower correlations were also found between number of rows and working width $(r=0.70)$, and also between weight and tank capacity $(r=0.64)$. Comparatively, lower correlation coefficients of the combined implements are caused by large variability and possible different combinations of cultivating elements, while the database and considered description of the implements did not include detailed information on tillage equipment and exact combination of soil-engaged devices with seeding machines.

Table 5. Correlation matrix of Pearson coefficient $r$ for functional parameters of combined planters.

\begin{tabular}{|c|c|c|c|c|c|c|}
\hline $\begin{array}{l}\text { Combined } \\
\text { Planters, } r\end{array}$ & $\begin{array}{l}\text { Required } \\
\text { Power, kW }\end{array}$ & $\begin{array}{l}\text { Working } \\
\text { Width, m }\end{array}$ & $\begin{array}{c}\text { Number of } \\
\text { Rows }\end{array}$ & $\begin{array}{c}\text { Tank } \\
\text { Capacity, L }\end{array}$ & Weight, kg & $\begin{array}{c}\text { Price VAT } \\
\text { Excluded, } €\end{array}$ \\
\hline Required power & 1 & & & & & \\
\hline Working width & 0.389 & 1 & & & & \\
\hline Number of rows & 0.379 & 0.697 & 1 & & & \\
\hline Tank capacity & 0.061 & 0.359 & 0.452 & 1 & & \\
\hline Weight & 0.287 & 0.281 & 0.645 & 0.644 & 1 & \\
\hline Price VAT excl. & 0.494 & 0.439 & 0.749 & 0.622 & 0.879 & 1 \\
\hline
\end{tabular}

Due to the combination of the seeding devices with tillage tools, the combined models of seeding machines are consequently heavier, resulting in predictably higher correlations associated with weight. According to the linear regression output, the starting investment can be considered to be $8602 €$ and increased by $14,320 €$ per each tonne of the machine (Table 6 ).

Table 6. Linear coefficient and intercept matrix for functional parameters of combined planters.

\begin{tabular}{|c|c|c|c|c|c|c|c|}
\hline & $\begin{array}{l}\text { Combined } \\
\text { Planters }\end{array}$ & $\begin{array}{c}\text { Required } \\
\text { Power, kW }\end{array}$ & $\begin{array}{l}\text { Working } \\
\text { Width, m }\end{array}$ & $\begin{array}{l}\text { Number } \\
\text { of Rows }\end{array}$ & $\begin{array}{c}\text { Tank } \\
\text { Capacity, L }\end{array}$ & $\begin{array}{l}\text { Weight, } \\
\text { kg }\end{array}$ & $\begin{array}{c}\text { Price VAT } \\
\text { Excluded, } €\end{array}$ \\
\hline \multirow{6}{*}{$m$} & Required power & & 17.22 & 2.152 & 0.005 & 0.008 & 0.0009 \\
\hline & Working width & 0.009 & & 0.086 & 0.0006 & 0.0002 & $1.718 \mathrm{E}-05$ \\
\hline & Number of rows & 0.067 & 5.622 & & 0.007 & 0.003 & 0.0002 \\
\hline & Tank capacity & 0.703 & 193.5 & 30.24 & & 0.221 & 0.013 \\
\hline & Weight & 10.28 & 443.4 & 126.7 & 1.876 & & 0.054 \\
\hline & Price VAT excl. & 261.6 & 11260 & 2379 & 29.52 & 14.32 & \\
\hline \multirow{6}{*}{$q$} & Required power & & 59.99 & 55.61 & 114.4 & 93.59 & 73.54 \\
\hline & Working width & 2.509 & & 0.984 & 2.730 & 3.076 & 2.731 \\
\hline & Number of rows & 22.54 & 9.723 & & 21.34 & 20.84 & 18.40 \\
\hline & Tank capacity & 1260 & 552.2 & 341.7 & & 635.4 & 611.6 \\
\hline & Weight & 1764 & 1191 & -1021 & 430.5 & & 165.9 \\
\hline & Price VAT excl. & 19,744 & 7895 & $-22,766$ & 11,309 & 8602 & \\
\hline
\end{tabular}

\subsubsection{No-Tillage Planters}

No-tillage cultivation approach requires specific and accurate selection of applied implements, due to its inherent difference from conventional farm management. The planter is combined with varying seed metering and conveying devices, and includes deeper furrows due to the planting operation applied on the field of crop residues without preliminary seedbed preparation and tillage [37]. For this reason, the planting process is characterized by a certain level of difficulty, and by a critical influence on the success of subsequent growing phases [38,39]. 
For a no-tillage group of seeding implements, high Pearson coefficients (Table 7) were defined between working width and power $(r=0.83)$; slightly lower values could be recognised between price and working width $(r=0.77)$, and between price and weight $(r=0.76)$. Relatively low correlations of the current group of implements could be caused by three main aspects: the large variability of the models available in the market intended for no-tillage planting, the different construction and design of the soil-engaged working elements (furrow) and the comparatively limited number of models included in the research.

Table 7. Correlation matrix of Pearson coefficient $r$ for functional parameters of no-tillage planters.

\begin{tabular}{cccccc}
\hline $\begin{array}{c}\text { No-Tillage } \\
\text { Planters, } \boldsymbol{r}\end{array}$ & $\begin{array}{c}\text { Required } \\
\text { Power, } \mathbf{k W}\end{array}$ & $\begin{array}{c}\text { Working } \\
\text { Width, } \mathbf{m}\end{array}$ & $\begin{array}{c}\text { Tank } \\
\text { Capacity, } \mathbf{L}\end{array}$ & Weight, kg & $\begin{array}{c}\text { Price VAT } \\
\text { Excluded, } \boldsymbol{\epsilon}\end{array}$ \\
\hline $\begin{array}{c}\text { Required power } \\
\text { Working width }\end{array}$ & 1 & & & & \\
Tank capacity & 0.835 & 1 & & & \\
Weight & 0.629 & 0.506 & 1 & 1 & \\
Price VAT excl. & 0.604 & 0.555 & 0.552 & 0.763 & 1 \\
\hline
\end{tabular}

As in the case of combined seeding machines, this group of planters is populated as well with heavy models. Due to the presence of residues, the planting process meets more resistance and requires more pressure on the soil-engaged devices, which is provided in this case by the weight of the machine itself. According to the output of linear regression analysis (Table 8) $5.9 \mathrm{~kW}$ need to be taken into account as a minimum required power and increased by $21.5 \mathrm{~kW}$ for each meter of working width. Concerning the weight and price correlation, 24,510 $€$ have to be considered as an initial investment, increased by $9601 €$ for each tonne of the machine. In comparison with other considered groups of planters, no-tillage implements require higher financial investments.

Table 8. Linear coefficient and intercept matrix for functional parameters of no-tillage planters.

\begin{tabular}{|c|c|c|c|c|c|c|}
\hline & No-Tillage Planters & $\begin{array}{l}\text { Required } \\
\text { Power, kW }\end{array}$ & $\begin{array}{l}\text { Working } \\
\text { Width, m }\end{array}$ & $\begin{array}{c}\text { Tank } \\
\text { Capacity, L }\end{array}$ & Weight, kg & $\begin{array}{l}\text { Price VAT } \\
\text { Excluded, } €\end{array}$ \\
\hline \multirow{5}{*}{$m$} & Required power & & 21.49 & 0.033 & 0.007 & 0.0008 \\
\hline & Working width & 0.032 & & 0.001 & 0.0003 & $3.901 \mathrm{E}-05$ \\
\hline & Tank capacity & 12.05 & 249.9 & & 0.172 & 0.015 \\
\hline & Weight & 24.80 & 877.6 & 1.767 & & 0.060 \\
\hline & Price VAT excl. & 469.6 & 15425 & 23.90 & 9.601 & \\
\hline \multirow{5}{*}{$q$} & Required power & & 5.873 & 52.18 & 65.93 & 43.02 \\
\hline & Working width & 0.999 & & 2.738 & 2.623 & 1.580 \\
\hline & Tank capacity & 79.84 & 186.9 & & 525.6 & 281.3 \\
\hline & Weight & 1500 & 289.6 & 1676 & & 81.43 \\
\hline & Price VAT excl. & 17,952 & -288.8 & 32,485 & 24,510 & \\
\hline
\end{tabular}

\subsubsection{Precision Planters}

The biggest group of considered data in current research is created by precision planters, which have high level of construction and operational complexity. Precision planters are used for application of horticultural and field crops characterized by high cultivation needs and high income (as sorghum, maize, sunflower, soybeans, and cotton) and designed to dispense seeds at the specific rate and in a specific pattern. Correct transversal and longitudinal spacing allow an optimal development without additional thinning.

In comparison with above mentioned three groups, linear regression analysis for precision planters have shown quite high correlations between almost all variables (Table 9), in particular between tank capacity and number of rows $(r=0.80)$, working width and power $(r=0.78)$, as well as between weight and power $(r=0.78)$. 
Table 9. Correlation matrix of Pearson coefficient $r$ for functional parameters of precision planters.

\begin{tabular}{ccccccc}
\hline $\begin{array}{c}\text { Precision } \\
\text { Planters, } \boldsymbol{r}\end{array}$ & $\begin{array}{c}\text { Required } \\
\text { Power, } \mathbf{k W}\end{array}$ & $\begin{array}{c}\text { Working } \\
\text { Width, } \mathbf{m}\end{array}$ & $\begin{array}{c}\text { Number of } \\
\text { Rows }\end{array}$ & $\begin{array}{c}\text { Tank } \\
\text { Capacity, } \mathbf{L}\end{array}$ & Weight, kg & $\begin{array}{c}\text { Price VAT } \\
\text { Excluded, } \boldsymbol{\epsilon}\end{array}$ \\
\hline Required power & 1 & & & & & \\
Working width & 0.783 & 1 & & & & \\
Number of rows & 0.773 & 0.709 & 1 & & & \\
Tank capacity & 0.694 & 0.577 & 0.796 & 1 & 1 & \\
Weight & 0.787 & 0.608 & 0.700 & 0.724 & 0.774 & 1 \\
Price VAT excl. & 0.598 & 0.509 & 0.703 & 0.774 & \\
\hline
\end{tabular}

According to the relatively high correlation between power and working width, $26.6 \mathrm{~kW}$ have to be considered as a minimum needed power, increasing by $10.6 \mathrm{~kW}$ per each meter of working width. With reference to the power-weight correlation, each additional $\mathrm{kW}$ of power increases the weight of the machine by $21.3 \mathrm{~kg}$ (Table 10).

Table 10. Linear coefficient and intercept matrix for functional parameters of precision planters.

\begin{tabular}{|c|c|c|c|c|c|c|c|}
\hline & $\begin{array}{l}\text { Precision } \\
\text { Planters }\end{array}$ & $\begin{array}{c}\text { Required } \\
\text { Power, kW }\end{array}$ & $\begin{array}{l}\text { Working } \\
\text { Width, m }\end{array}$ & $\begin{array}{l}\text { Number } \\
\text { of Rows }\end{array}$ & $\begin{array}{c}\text { Tank } \\
\text { Capacity, L }\end{array}$ & $\begin{array}{c}\text { Weight, } \\
\text { kg }\end{array}$ & $\begin{array}{c}\text { Price VAT } \\
\text { Excluded, } €\end{array}$ \\
\hline \multirow{6}{*}{$m$} & Required power & & 10.61 & 7.374 & 0.112 & 0.029 & 0.001 \\
\hline & Working width & 0.058 & & 0.505 & 0.007 & 0.001 & 6.71E-05 \\
\hline & Number of rows & 0.081 & 0.996 & & 0.013 & 0.002 & 0.0001 \\
\hline & Tank capacity & 4.309 & 48.29 & 47.41 & & 0.159 & 0.008 \\
\hline & Weight & 21.32 & 231.0 & 188.9 & 3.279 & & 0.039 \\
\hline & Price VAT excl. & 334.9 & 3869 & 3799 & 70.25 & 15.51 & \\
\hline \multirow{6}{*}{$q$} & Required power & & 26.63 & 21.38 & 37.53 & 28.57 & 40.96 \\
\hline & Working width & 0.013 & & 0.750 & 2.049 & 1.757 & 2.239 \\
\hline & Number of rows & 0.884 & 2.484 & & 2.660 & 2.799 & 3.026 \\
\hline & Tank capacity & -14.36 & 92.63 & -20.85 & & 59.15 & 59.46 \\
\hline & Weight & -77.88 & 492.2 & 196.5 & 483.8 & & 394.7 \\
\hline & Price VAT excl. & 3295 & 11,132 & 2036 & 6546 & 4601 & \\
\hline
\end{tabular}

\subsection{Multiple Linear Modelling}

In the simulation and modelling with different scenarios for optimisation of agricultural machinery management, some functional parameters play a particularly important role. The needed power is relevant to understand the availability and suitability of tractors fleet, in relation to time/schedule management and power correspondence. The required power also has an essential importance in the fuel consumption aspect, which is eventually determining the environmental impact regarding gas emissions. The weight of the machine is closely related to the soil stress and compaction, especially in the case of planters, where some models are extremely heavy due to the crop/farm management approach (tillage/no-tillage components) and seed/fertilizer tank availability. Carbon footprint related to implemented machinery has to be also considered, where perceived management plays a vital role. Working width relates to the productivity of the process and timing. Finally, the price has a direct influence on the farm economy, financial resource management, assessment of the investments and possible profit expectations. Additionally, price is also needed in many DSS applications and models as an input data as e.g. in $[11,18,30,40]$ where optimization of costs is needed to schedule most profitable management conditions. In order to improve the proposed models and their predictive capacity, needed power, weight, working width, and price underwent multiple linear regression analysis, thus excluding number of rows, tank capacity, etc. Additionally, the price was considered only as a dependent variable in the models. The results of stepwise regression analysis, considering the mentioned functional parameters and price as responsible variables are summarised in Table 11. 
Table 11. Equation models for response variables (power, weight, working width, price) determined by stepwise regression analysis (C—-tank capacity, L; M-weight, kg; P-power, kW; L-working width, $\mathrm{m}$; Pr-estimated price for different groups of machines, $€$.).

\begin{tabular}{cccc}
\hline & Power & Adjusted $\boldsymbol{R}^{\mathbf{2}}$ & Standard Error \\
\hline Row & $\mathrm{P}=33.95+4.07 \mathrm{~L}+0.013 \mathrm{M}$ & 0.818 & 12.55 \\
Combined & $\mathrm{P}=50.33-0.022 \mathrm{C}+18.48 \mathrm{~L}+0.01 \mathrm{M}$ & 0.243 & 40.45 \\
No-tillage & $\mathrm{P}=3.44+20 \mathrm{~L}+0.019 \mathrm{C}-0.004 \mathrm{M}$ & 0.770 & 14.39 \\
Precision & $\mathrm{P}=16.62+6.2 \mathrm{~L}+0.021 \mathrm{C}+0.015 \mathrm{M}$ & 0.776 & 9.50 \\
\hline \multicolumn{1}{c}{ Weight } & Adjusted $\boldsymbol{R}^{\mathbf{2}}$ & Standard Error \\
\hline Row & $\mathrm{M}=-2271+44.07 \mathrm{P}+0.89 \mathrm{C}$ & 0.848 & 743 \\
Combined & $\mathrm{M}=-494.8+7.91 \mathrm{P}+1.85 \mathrm{C}$ & 0.451 & 1234 \\
No-tillage & $\mathrm{M}=179-33.8 \mathrm{P}+1190 \mathrm{~L}+1.65 \mathrm{C}$ & 0.444 & 1374 \\
Precision & $\mathrm{M}=-57.1+15.08 \mathrm{P}+1.45 \mathrm{C}$ & 0.673 & 310.8 \\
\hline & Working Width & Adjusted $\boldsymbol{R}^{\mathbf{2}}$ & Standard Error \\
\hline Row & $\mathrm{L}=0.25+0.012 \mathrm{P}+0.0018 \mathrm{C}+0.0016 \mathrm{M}$ & 0.777 & 0.471 \\
Combined & $\mathrm{L}=1.77+0.0095 \mathrm{P}+0.0005 \mathrm{C}$ & 0.236 & 0.964 \\
No-tillage & $\mathrm{L}=0.75+0.028 \mathrm{P}+0.0001 \mathrm{M}$ & 0.743 & 0.591 \\
Precision & $\mathrm{L}=0.013+0.058 \mathrm{P}$ & 0.610 & 0.925 \\
\hline & Price & Adjusted $\boldsymbol{R}^{\mathbf{2}}$ & Standard Error \\
\hline Row & $\operatorname{Pr}=-308.5+9.77 \mathrm{M}-60.82 \mathrm{P}+1767 \mathrm{~L}+4.95 \mathrm{C}$ & 0.972 & 3490 \\
Combined & $\mathrm{Pr}=-4490+11.63 \mathrm{M}+191.1 \mathrm{P}$ & 0.826 & 10,750 \\
No-tillage & $\mathrm{Pr}=-2038+6.04 \mathrm{M}+10122 \mathrm{~L}$ & 0.750 & 11,600 \\
Precision & $\mathrm{Pr}=4840+11.64 \mathrm{M}-104.8 \mathrm{P}+44.46 \mathrm{C}$ & 0.694 & 6230 \\
\hline
\end{tabular}

Results of multiple linear regression analysis showed predictable effects and corresponding correlations as in the case of linear regression analysis. According to the database population and models variability, better forecasting models were obtained for row drills and precision planters, while for combined and no-till planters the models were less robust.

With regard to the power, it can be noticed how row, no-tillage and precision planters power are clearly influenced by working width and weight, exhibiting robust models with adjusted $\mathrm{R}^{2}$, in general, higher than 0.77. Only combined machines, still less common in the market and featuring several different configurations, cannot be characterised through a highly predictive equation.

The same behaviour can be recognised in the case of working width, even if with slightly lower correlations arising from the multiple regression. In all of the cases working width can be related to the needed power. Additionally, for row and no-tillage machines, the models encompass the weight, while in the case of combined and row seeders the tank capacity is included by the multiple linear models. As for the power and for the same reason, a less predictive model was found in the case of combined machines.

In the case of weight, good correlations can be noticed for row and precision planters, and acceptable correlations can also be recognized in the case of combined and no-tillage machines. In all of the cases, the weight is a direct function of power and hopper capacity, while the working width plays a significant direct role only in the case of no-tillage machines.

Finally, highly predictive price models can be defined for all of the machines, with adjusted $\mathrm{R}^{2}$ values in general higher than 0.7 , which can be considered as an advantage for more deep analysis of price and costs of the farm. After multilinear regressions, multiple variables were included in the equations, meaning that different parameters independently influence the final market price. In all of the cases, the weight of the machine was primarily conditioning the final value, followed by needed power (which is not determinant only in the case of no-tillage machines). Tank capacity and working width play a relevant role for two groups of machines: specifically, the hopper size is found in row and precision machines equation models, while the width is found in no-tillage and row models. 


\section{Conclusions}

The definition of the best seeding machine is an issue for a farm. Indeed opposite constraints are influencing such choice: weather and soil condition often reduce the total time available to enter the field in such a way that large areas have to be seeded in a few days or even in a few hours. Larger machines not only are inducing higher investments but also are having secondary effects due to larger widths, higher weights, and larger needed tractors. Indeed increased dimensions are affecting manoeuvrability, as well as environmental impact (due to construction energy and power consumption). Furthermore, the choice of the machine is additionally constrained by the maximum power of the tractors already available in the farm fleet. In order to help the definition of the best trade-off, and to support analysis and simulations, reference equation models were developed with the application of operation research approach for seeding machines. Linear and multiple linear regression analyses were proposed to develop forecasting models for four group of planters. Main functional parameters were defined, and correlations were determined. According to the two-level modelling (linear/multiple linear), comparatively similar correlations were obtained. Thus, the needed power, weight, working with and the price of the machine can be identified with the application of developed models. In the case of linear regression analysis, simple models allow to calculate and predict needed functional parameters and can, therefore, be applied by farmers and stakeholders for simple optimisation of the machinery selection process. Nevertheless, for a deep and more accurate identification of the parameters relations multiple linear regression equations can be applied, reducing the eventuality of possible misleading or overfitting of data. Implementation of these models might create some constraints, however can be successfully used by regional, national authorities and other stakeholders of the field for deeper analysis and assessment of technical and financial expenses.

According to the results arising from the two applied methods, significant relations of the weight as an independent variable were determined for all seeder groups, and for different variables. On the other hand, power and price relations and also working width could be recognized to be relevant mainly for precision and seed drills. Finally, the implements intended for combined and no-tillage seeding process gave evidence of variable behaviour, mainly caused by the presence of large variability of soil-engaged devices and different possible combined elements designs.

Author Contributions: The authors equally contributed to the present study.

Funding: This research received no external funding.

Acknowledgments: The authors would like to thank the editor and the three anonymous reviewers for the insightful and constructive suggestions raised during the review stage. The research has been partially supported by PRIN 2015 2015KTY5NW “Optimization of operating machinery through the mission profile analysis for a more efficient agriculture". Research activity of T.Y. is supported by a PhD grant issued by Fondazione Cassa di Risparmio di Padova e Rovigo (CARIPARO).

Conflicts of Interest: The authors declare no conflict of interest.

\section{References}

1. Gass, G.; Biggs, S.; Kelly, A. Stakeholders, science and decision making for rural mechanization and development poverty-focused. World Dev. 1997, 25, 115-126. [CrossRef]

2. Reidsma, P.; Janssen, S.; Jansen, J.; van Ittersum, M.K. On the development and use of farm models for policy impact assessment in the European Union-A review. Agric. Syst. 2018, 159, 111-125. [CrossRef]

3. Cavallo, E.; Ferrari, E.; Bollani, L.; Coccia, M. Attitudes and behaviour of adopters of technological innovations in agricultural tractors: A case study in Italian agricultural system. Agric. Syst. 2014, 130, 44-54. [CrossRef]

4. Walley, K.; Custance, P.; Taylor, S.; Lindgreen, A.; Hingley, M. The importance of brand in the industrial purchase decision: A case study of the UK tractor market. J. Bus. Ind. Mark. 2007, 22, 383-393. [CrossRef]

5. Jianying, F.; Peng, L.; Weisong, M.; Xiaoshuan, Z.; Zetian, F. Farmers brand perception toward agricultural machinery in China. Afr. J. Agric. Res. 2011, 6, 1966-1971. 
6. Sims, B.; Heney, J. Promoting smallholder adoption of conservation agriculture through mechanization services. Agriculture 2017, 7, 64. [CrossRef]

7. Bainer, R.; Kepner, R.A.; Barger, E.L. Principles of Farm Machinery; John Wley Sons Inc.: New York, NY, USA, 1955.

8. Murray, J.R.; Tullberg, J.N.; Basnet, B.B. Planters and their Components: Types, Attributes, Functional Requirements, Classification and Description; Australian Centre for International Agricultural Research: Canberra, Australia, 2006.

9. Cupiał, M.; Szelag-Sikora, A.; Niemiec, M. Optimisation of the machinery park with the use of OTR-7 software in context of sustainable agriculture. Agric. Agric. Sci. Procedia 2015, 7, 64-69. [CrossRef]

10. Edwards, W. Estimating Farm Machinery Repair Costs; Iowa State University Extension and Outreach: Ames, IA, USA, 2015.

11. Fountas, S.; Carli, G.; Sørensen, C.G.; Tsiropoulos, Z.; Cavalaris, C.; Vatsanidou, A.; Tisserye, B. Farm management information systems: Current situation and future perspectives. Comput. Electron. Agric. 2015, 115, 40-50. [CrossRef]

12. Søgaard, H.T.; Sørensen, C.G. A model for optimal selection of machinery sizes within the farm machinery system. Biosyst. Eng. 2004, 89, 13-28. [CrossRef]

13. Sørensen, C.G.; Bochtis, D.D. Conceptual model of fleet management in agriculture. Biosyst. Eng. 2010, 105, 41-50. [CrossRef]

14. Glen, J.J. Feature article-Mathematical models in farm planning: A survey. Oper. Res. 1987, 35, 641-666. [CrossRef]

15. Weintraub, A.; Romero, C. Operations research models and the management of agricultural and forestry resources: A review and comparison. Interfaces (Providence) 2006, 36, 446-457. [CrossRef]

16. Filippi, C.; Mansini, R.; Stevanato, E. Mixed integer linear programming models for optimal crop selection. Comput. Oper. Res. 2017, 81, 26-39. [CrossRef]

17. Gass, G.M.; Biggs, S.D. Rural mechanisation: A review of processes, policies, practice and literature. Proj. Apprais. 1993, 8, 157-187. [CrossRef]

18. Nikkilä, R.; Seilonen, I.; Koskinen, K. Software architecture for farm management information systems in precision agriculture. Comput. Electron. Agric. 2010, 70, 328-336. [CrossRef]

19. Yousif, L.A.; Dahab, M.H.; El Ramlawi, H.R. Crop-machinery management system for farm cost analysis. Int. J. Sci. Technol. Res. 2013, 2, 11.

20. Pezzuolo, A.; Basso, B.; Marinello, F.; Sartori, L. Using SALUS model for medium and long term simulations of energy efficiency in different tillage systems. Appl. Math. Sci. 2014, 8, 6433-6445. [CrossRef]

21. Bulgakov, V.; Pascuzzi, S.; Nadykto, V.; Ivanovs, S. A mathematical model of the plane-parallel movement of an asymmetric machine-and-tractor aggregate. Agriculture 2018, 8, 151. [CrossRef]

22. Lassen, P.; Lamandé, M.; Stettler, M.; Keller, T.; Jørgensen, M.S.; Lilja, H. Terranimo ${ }^{\circledR} — A$ soil compaction model with internationally compatible input options. In Proceedings of the EFITA-WCCA-CIGR Conference Sustainable Agriculture through ICT Innovation, Turin, Italy, 24-27 June 2013.

23. Chamen, T. Controlled traffic farming-From worldwide research to adoption in Europe and its future prospects. Acta Technol. Agric. 2015, 18, 64-73. [CrossRef]

24. Al-Mansour, F.; Jejcic, V. A model calculation of the carbon footprint of agricultural products: The case of Slovenia. Energy 2017, 136, 7-15. [CrossRef]

25. Bender, D.; Kline, D.; McCarl, B. Postoptimal linear programming analysis of farm machinery. Trans. ASAE 1990, 33, 0015-0020. [CrossRef]

26. Zarco-Tejada, P.; Hubbard, N.; Loudjani, P. Precision Agriculture: An Opportunity for EU Farmers-Potential Support with the CAP 2014-2020; Joint Research Centre (JRC) of the European Commission: Brussels, Belgium, 2014.

27. Sims, B.; Kienzle, J. Sustainable agricultural mechanization for smallholders: What is it and how can we implement it? Agriculture 2017, 7, 50. [CrossRef]

28. Camarena, E.A.; Gracia, C.; Cabrera Sixto, J.M. A mixed integer linear programming machinery selection model for multifarm systems. Biosyst. Eng. 2004, 87, 145-154. [CrossRef]

29. Hameed, I.A.; Bochtis, D.D.; Sørensen, C.G.; Vougioukas, S. An object-oriented model for simulating agricultural in-field machinery activities. Comput. Electron. Agric. 2012, 81, 24-32. [CrossRef]

30. Sopegno, A.; Calvo, A.; Berruto, R.; Busato, P.; Bocthis, D. A web mobile application for agricultural machinery cost analysis. Comput. Electron. Agric. 2016, 130, 158-168. [CrossRef] 
31. Fountas, S.; Sorensen, C.G.; Tsiropoulos, Z.; Cavalaris, C.; Liakos, V.; Gemtos, T. Farm machinery management information system. Comput. Electron. Agric. 2015, 110, 131-138. [CrossRef]

32. Sofi, N.A.; Ahmed, A.; Ahmad, M.; Bhat, B.A. Decision making in agriculture: A linear programming approach. Int. J. Mod. Math. Sci. 2015, 13, 160-169.

33. Guadalajara-Olmeda, N.; Loreto Fenollosa-Ribera, M. Modelos de valoración de maquinaria agrícola en el sur de Europa. Un análisis de la depreciación real. Valuation models of agricultural machinery in southern Europe. An analysis of real depreciation. Agrociencia 2010, 44, 381-391.

34. Clarke, L.J. Strategies for Agricultural Mechanization Development: The Roles of the Private Sector and the Government; Agricultural Support Systems Division, Food and Agriculture Organisation of the United Nations (FAO): Rome, Italy, 2000.

35. Sørensen, C.G.; Fountas, S.; Nash, E.; Pesonen, L.; Bochtis, D.; Pedersen, S.M.; Basso, B.; Blackmore, S.B. Conceptual model of a future farm management information system. Comput. Electron. Agric. 2010, 72, 37-47. [CrossRef]

36. Hunt, D. Farm Power and Machinery Management, 8th ed.; Waveland Press: Long Grove, IL, USA, 1983.

37. Sharipov, G.M.; Paraforos, D.S.; Griepentrog, H.W. Modelling and simulation of the dynamic performance of a no-till seeding assembly with a semi-active damper. Comput. Electron. Agric. 2017, 139, 187-197. [CrossRef]

38. Vincent-Caboud, L.; Peigné, J.; Casagrande, M.; Silva, E. Overview of organic cover crop-based no-tillage technique in Europe: Farmers' practices and research challenges. Agriculture 2017, 7, 42. [CrossRef]

39. Pezzuolo, A.; Dumont, B.; Sartori, L.; Marinello, F.; De Antoni Migliorati, M.; Basso, B. Evaluating the impact of soil conservation measures on soil organic carbon at the farm scale. Comput. Electron. Agric. 2017, 135, 175-182. [CrossRef]

40. Bochtis, D.D.; Sørensen, C.G.C.; Busato, P. Advances in agricultural machinery management: A review. Biosyst. Eng. 2014, 126, 69-81. [CrossRef]

(C) 2018 by the authors. Licensee MDPI, Basel, Switzerland. This article is an open access article distributed under the terms and conditions of the Creative Commons Attribution (CC BY) license (http://creativecommons.org/licenses/by/4.0/). 